\title{
Antibody-based detection of alkaline phosphatase in lepidopteran insects (Lepidoptera: Noctuidae)
}

\author{
R.A. Khan ${ }^{1}$, M. Rashid ${ }^{1}$, D. Wang ${ }^{2}$ and Y.L. Zhang ${ }^{1}$ \\ ${ }^{1}$ Key Laboratory of Plant Protection Resources and Pest Management, \\ Ministry of Education, College of Plant Protection, \\ Northwest A\&F University, Yangling, Shaanxi, China \\ ${ }^{2}$ Institute of Entomology, Northwest A\&F University, Yangling, Shaanxi, China \\ Corresponding authors: Y.L. Zhang / D. Wang \\ E-mail: yalinzh@yahoo.com / wanghande@yahoo.com
}

Genet. Mol. Res. 12 (4): 4371-4382 (2013)

Received October 23, 2012

Accepted February 4, 2013

Published October 10, 2013

DOI http://dx.doi.org/10.4238/2013.October.10.3

\begin{abstract}
Alkaline phosphatase (ALP) of Helicoverpa armigera Hub. (Lepidoptera; Noctuidae) (GenBank accession No. EU729322) was cloned and expressed. The target gene H.a-ALP, having an open reading frame of $1608 \mathrm{bp}$, was reverse-transcribed from cDNA by the polymerase chain reaction. The open reading frame of the target gene was cloned into the pET-32a expression vector to obtain recombinant protein in Escherichia coli DE-3 cells for the subsequent production of polyclonal antibody. New Zealand white rabbits were used for production of antipET-32a-H.a-ALP. The production of antibody was also optimized by employing ELISA for titer determination. The produced antiserum was processed and used as an antibody. Western blot results showed that the polyclonal antibody produced was capable of effectively binding target protein not only from $H$. armigera but also from other lepidopterans such as Mythimna separata and Plutella xylostella. This antibody was also used to detect levels of ALP within different instars of $H$. armigera. Thus, it is concluded that this antibody-based assay is very useful for the effective detection of gene-specific expression. Furthermore, it may also be used to detect the expression levels and tissue localization of ALP, as well as in
\end{abstract}


other physiological studies involving this enzyme.

Key words: Alkaline phosphatase; pET-32a expression vector; ELISA; Helicoverpa armigera Hub.; Polyclonal antibody

\section{INTRODUCTION}

The American bollworm Helicoverpa armigera Hübner (Lepidoptera: Noctuidae) is considered to be one of the major pests of cotton, legumes, and more than 100 other plant species (Bhatnagar et al., 1982). H. armigera is a ubiquitous pest, and its presence has been recorded in Asia, Europe, Australia, and Africa (EPPO, 1996). Global yield loss from this pest is amounting to US $\$ 2$ billion annually (ICRISAT, 2003).

Alkaline phosphatases (ALPs; E.C. 3.1.3.1) are abundant enzymes, involved mainly in removing phosphate groups from organic molecules. The wide distribution of ALPs suggests their fundamental roles in cells. ALPs have common properties in hydrolase/transferase reactions, dimeric structure, activity dependence on $\mathrm{Zn}$ and $\mathrm{Mg}$, and identical amino acid sequences around the active site (Eguchi, 1995). In insects, ALPs are involved in several biological processes and respond to stress, pathogenesis, or infection (Kucera and Weiser, 1974; Sujak et al., 1978; Chang et al., 1993; Eguchi, 1995; Sukhanova et al., 1996; Miao, 2002). ALP is one important synthesizing enzyme of tyrosine, the precursor of dopamine and octopamine, which are known to take part in the control of levels of insect developmental hormones, juvenile hormone, and 20-hydroxyecdysone (20E) (Wright, 1987; Rauschenbach et al., 2007a,b).

ALP is a hydrolytic enzyme, which hydrolyzes phosphomonoesters under alkaline conditions. It is found mainly in the intestinal epithelium of animals, and its primary function is to provide phosphate ions from mononucleotide and ribonucleoproteins for a variety of metabolic processes. The enzyme is also involved in the transphosphorylation reaction (Sakharov et al., 1989). Any impairment in its activity will affect the physiology of the insect gut. This enzyme is located in the midgut, Malpighian tubules, muscles, and nerve fibers of the lepidopertan insects (Horie, 1958). The midgut has the highest ALP activity as compared with other tissues. The highest activity appeared before the full appetite gluttonous stage (Miao, 2002; Senthil-Nathan et al., 2005) of the fifth instar, and the lowest activity was found in the mature larval stage (Miao, 2002). High levels of ALP have also been implicated in insecticide resistance in pests (Srinivas et al., 2004; Zibaee et al., 2009).

In light of the above-mentioned facts, it is clear that ALP not only plays very important roles in insect metabolism but also in resistance towards insecticides. In this report, using recombinant fusion protein, we have successfully produced a high-titer antibody against pET-32a-H.a-ALP. This antibody-based assay system was developed to detect ALP from $H$. armigera. In addition, owing to the close homology of the ALP gene, we have also used this system to detect ALPs in other lepidopterans.

\section{MATERIAL AND METHODS}

\section{Insects}

H. armigera, Mythimna separata, and Plutella xylostella larvae were procured from 
Zhongke Baiyun Industry Co., Ltd. Beijing, China and reared until F1 for use in the bioassay. Groups of 24 larvae were placed into 24-chamber plastic boxes obtained from the company. The boxes were placed in an incubator at $27+1^{\circ} \mathrm{C}$ and 40 to $50 \%$ relative humidity (RH), with a 12-h photoperiod. After pupation, pupae were collected and placed in a plastic jar having cotton cloth on both sides and a vial placed in the middle with $10 \%$ sugar solution dispensed through the cotton. Eggs were collected on the lower and upper cotton cloth and placed in transparent plastic bags for emergence.

\section{Insect diet}

Cotton bollworms were reared in the laboratory on a modified semi-synthetic diet (Ahmed and McCaffery, 1991), consisting of chickpea flour, ascorbic acid, Wesson's salt, vitamins (ABDEC), Brewer's yeast, choline chloride, agar agar, formaldehyde, streptomycin sulfate, and methyl- $p$-hydroxybenzoate, under laboratory conditions of $27 \pm 2^{\circ} \mathrm{C}, 65 \pm 5 \% \mathrm{RH}$, and 14:10 h light:dark. A homogeneous stock of third-instar larvae was obtained for respective insecticidal treatments. M. separata larvae were fed fresh wheat leaves, whereas P. xylostella larvae were fed cabbage.

\section{RNA extraction}

Total RNA was extracted from the frozen insects at $-80^{\circ} \mathrm{C}$. Insects were homogenized using liquid nitrogen before addition of RNAiso Plus (TaKaRa). RNA was extracted following the manufacturer instructions. The quality of RNA samples was examined by running on an agarose gel. DNase-I (Fermentas) was used to remove DNA contamination.

\section{cDNA construction}

cDNA was synthesized by reverse transcription using RevertAid ${ }^{\mathrm{TM}}$ Reverse Transcriptase (Fermentas). The $20-\mu \mathrm{L}$ reaction contained $5 \mu \mathrm{L}$ total RNA (having $1 \mu \mathrm{g}$ RNA), 1 $\mu \mathrm{L}$ oligo $(\mathrm{dT})_{18}$ primer, $4 \mu \mathrm{L} 5 \mathrm{X}$ reaction buffer, $2 \mu \mathrm{L} 10 \mathrm{mM}$ dNTP mix, and $1 \mu \mathrm{L} 200 \mathrm{U} /$ $\mu \mathrm{L}$ RevertAid ${ }^{\mathrm{TM}} \mathrm{M}-\mathrm{MuLV}$ Reverse Transcriptase. The reaction mixture was incubated for 60 min at $42^{\circ} \mathrm{C}$. The reaction was terminated by heating at $70^{\circ} \mathrm{C}$ for $10 \mathrm{~min}$, and the product was stored at $-80^{\circ} \mathrm{C}$.

\section{Gene cloning and sequencing}

The H. armigera alkaline phosphatase gene (GenBank Accession No. EU729322) was amplified from cDNA by the polymerase chain reaction (PCR) using upstream (5'-CGGGATCCATGGTGACACTGTTCCCGTACGT-3') and downstream (5'-CCG $\boldsymbol{A} \boldsymbol{A} \boldsymbol{G C}$ TTTTATCGCAGTAAAATGGAAGTGA-3') primers, respectively. A BamHI site was incorporated into the sense primer, whereas a HindIII site was incorporated into the antisense primer for the double-digestion reaction. The PCR amplification reaction was performed as follows: a first denaturation step for $3 \mathrm{~min}$ at $94^{\circ} \mathrm{C}$, followed by 30 cycles of $94^{\circ} \mathrm{C}$ for $30 \mathrm{~s}, 60^{\circ} \mathrm{C}$ for $45 \mathrm{~s}$, and $72^{\circ} \mathrm{C}$ for $2 \mathrm{~min}$, and then a final extension of $7 \mathrm{~min}$ at $72^{\circ} \mathrm{C}$. The PCR product was run on a $1 \%$ agarose $(\mathrm{w} / \mathrm{v})$ gel and visualized by ethidium bromide staining using a Bio-Rad 
imaging system (Bio-Rad Laboratories, Inc., Berkeley, California). The target gene-amplified product was gel purified using a gel extraction kit (Biomiga, Inc., San Diego, California). The gel-purified PCR product was then ligated to the pMD-19T vector (TaKaRa Bio Inc., Japan) and transformed into Escherichia coli DH5a. The transformants were selected on LB agar plates containing $100 \mu \mathrm{g} / \mathrm{mL}$ ampicillin after overnight incubation at $37^{\circ} \mathrm{C}$. Resultant PCR clones were sequenced by Shanghai Sunny Biotech Co., Ltd, China.

\section{Sequence and phylogenetic analyses}

Received sequences were analyzed using DNAMAN 6.0. The amino acid sequence was deduced using the ExPASy online tool (http://web.expasy.org/translate/). The amino acid sequence was used for a BLAST search against the NCBI database to determine its conformity with the original sequence.

\section{Construction of expression plasmid}

pMD-19T-H.a-ALP was double digested by BamHI and HindIII. The digested fragment was gel purified and ligated, using a TaKaRa quick ligation kit, to the prokaryotic expression vector $\mathrm{pET}-32 \mathrm{a}$ (Novagen) to make the recombinant plasmid pET-32a-H.a-ALP. The ligation reaction was transformed into BL-21 (DE-3) competent cells, which were cultured in LB medium containing $100 \mu \mathrm{g} / \mathrm{mL}$ ampicillin at $37^{\circ} \mathrm{C}$ and $220 \mathrm{rpm}$ until the absorbance reached 0.5 . Then, after adding isopropyl- $\beta$-D-thiogalactopyranoside (IPTG) at a final concentration of $1 \mathrm{mM}$, the culture was further incubated for $8 \mathrm{~h}$ at $30^{\circ} \mathrm{C}$ for expression of recombinant protein.

\section{Sodium dodecyl sulfate-polyacrylamide gel electrophoresis (SDS-PAGE) analysis of the recombinant protein}

The expressed recombinant protein was confirmed and visualized by $12 \%$ SDS-PAGE using standard protein markers (TaKaRa).

\section{Production and optimization of polyclonal antibody}

The recombinant protein was expressed in $300 \mathrm{~mL} \mathrm{LB}$, as mentioned above. The expressed protein was isolated by SDS-PAGE and purified from the gel using the BioRad Electro-Eluter, according to the manufacturer instructions. The purified protein was freezedried using a vacuum freeze dryer. Dried protein $(0.5 \mathrm{mg} / \mathrm{mL})$ was mixed 1:1 with complete Freund's adjuvant for immunization of New Zealand white rabbit. The antibody titer was optimized in three phases of the injection schedule. A rabbit was injected every two weeks during the first phase of immunization. In the second phase, the rabbit was injected with antigen mixed in phosphate-buffered saline (PBS) only, whereas in the third phase, the rabbit was injected with antigen mixed in incomplete Freund's adjuvant and PBS, respectively, at a 1 -week interval. At the end of every immunization phase, blood samples were collected at the 1-week time interval for titer determination. A total of six injections were performed to immunize the rabbit before terminal bleeding. ELISA was used to confirm the antibody titer, using a 
goat anti-rabbit IgG-HRP-conjugated secondary antibody. The 3,3',5,5'-tetramethylbenzidine substrate was used to determine the signal intensity at $450 \mathrm{~nm}$ using a microplate reader.

\section{Protein extraction and Western blot analysis}

Protein was extracted from insects frozen at $-80^{\circ} \mathrm{C}$ using the Trizol method (Chomczynski, 1993). After phase separation with chloroform, the protein was separated from the phenol-ethanol supernatant by 3 volumes of acetone precipitation. The precipitated proteins were washed three times with $0.3 \mathrm{M}$ guanidine hydrochloride in $95 \%$ ethanol. The purified protein was dissolved in $1 \%$ SDS. Western blotting was used to assess the binding of the polyclonal antibody produced against recombinant protein to alkaline phosphatase from insects.

\section{RESULTS}

Using gene-specific primers, a 1608-bp open reading frame (ORF) of H.a-ALP was amplified by PCR, as shown in Figure 1A. The fragment was then confirmed to be an ORF of H.a-ALP by DNA sequencing.

\section{Construction of expression recombinant vector}

The gel-purified ORF of H.a-ALP cloned to the pMD-19-T vector (Figure 1B) was digested by BamHI and HindIII. The resulting fragment was cloned into the expression vector pET-32a. The plasmid pET-32a-H.a-ALP was verified by restriction enzyme digestion and sequencing of the target gene (Figure 1C).

A single colony of pET-32a-H.a-ALP was grown for DNA extraction, and the resultant DNA was double-digested with BamHI and HindIII. Results upon agarose electrophoresis showed two bands of 5900 and 1608 bp, respectively (Figure 1C).



Figure 1. A. PCR amplification of the H.a-ALP gene. Lane $M=$ DNA marker; lane $1=$ H.a-ALP amplification product; B. Double restriction digestion of pMD-19T-H.a-ALP. Lane $M=$ DNA marker; lane $1=$ target band of 1608 bp. C. Double restriction digestion of the expression vector pET-32a-H.a-ALP; lane $M=$ DNA marker; lane 1 = target band of $1608 \mathrm{bp}$. 


\section{Expression optimization of recombinant protein}

The positive clones harboring pET-32a-H.a-ALP (Figure 2) for expression were confirmed by a double-digestion reaction. The E. coli BL-21 (DE-3)-expressed, IPTG-induced recombinant protein was detected by $12 \%$ SDS-PAGE using standard protein molecular weight markers (Figure 3). The expected band was detected at $79 \mathrm{kDa}$, as the MW of H.a-ALP is about $58.8 \mathrm{kDa}$ and the pET-32a tag is approximately $20.2 \mathrm{kDa}$. Protein expression was optimized at $6 \mathrm{~h}$ after induction with $1 \mathrm{mM}$ IPTG. The expressed recombinant protein was eluted from the gel using the Bio-Rad Electro-Eluter and confirmed by SDS-PAGE (Figure 4). The eluted protein from the gel was further dialyzed in a protein dialysis membrane to remove excess salts for $24 \mathrm{~h}$.

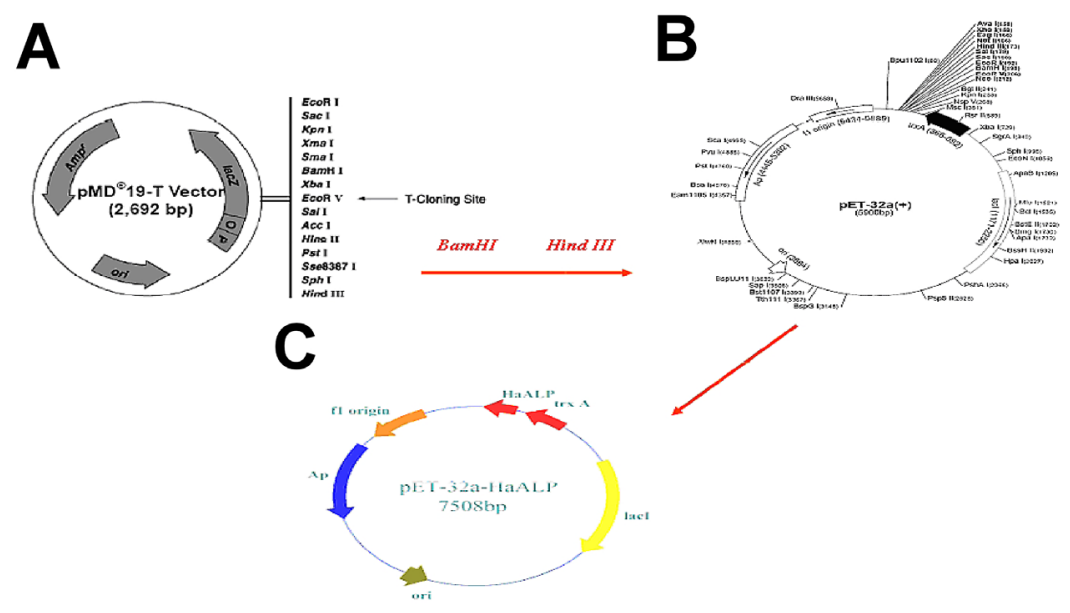

Figure 2. Construction of expression vector. A. pET32a-H.a-ALP. pMD19-T vector; B. pET32a expression vector; and C. recombinant vector with target gene.



Figure 3. Time course expression of pET32a-H.a-ALP recombinant protein. Lane $M=$ molecular weight marker. Lane 1 = DE-3 cells; lane $2=$ DE-3 cells with pET32a plasmid; lane $3=$ DE-3 cells with the recombinant vector without IPTG; lane 4-9 = expression optimization at different intervals from 1-6 h, respectively. 


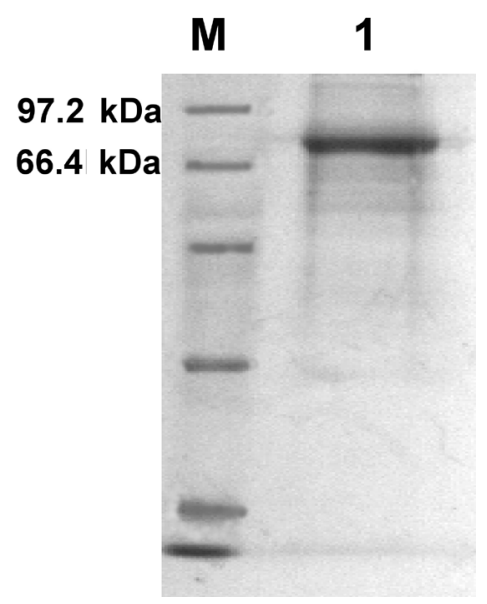

Figure 4. Purified recombinant protein pET-32a-H.a-ALP for production of anti-pET-32a-H.a-ALP. Lane $M=$ protein weight marker; lane 1 = purified pET-32a-H.a-ALP.

\section{Optimization of anti-pET32a-H.a-ALP titer}

Results of the ELISA showed increasing intensity for the first, second, and third blood tests, respectively (Figure 5A, B, and C). Analysis of optical density data recorded at 450 $\mathrm{nm}$ showed that after the first phase of immunization with the antigen pET32a-H.a-Alp in complete Freund's adjuvant, and in incomplete Freund's adjuvant and PBS, the antibody titer in the blood sample taken from the marginal ear vein was 1:128 (Figure 6). After the second phase of immunization with antigen in PBS, the antibody titer in test blood collected from the marginal ear vein reached 1:256 (Figure 7), but was still considered below the desired level. In the third and last phase, the antibody titer reached the desired level of 1:512 in the rabbit after immunization with antigen in incomplete Freund's adjuvant and followed by antigen in PBS (Figure 8). After reaching the desired antibody titer, terminal blood was collected from the rabbit. The blood was initially placed at $37^{\circ} \mathrm{C}$ overnight and then centrifuged at 12,000 rpm for 30 min to obtain serum with anti-pET32a-H.a-ALP.

\section{H. armigera protein quality determination}

The quality and quantity of the H. armigera protein extracted by the Trizol method were determined by $12 \%$ SDS-PAGE. The extracted protein showed clear bands of different sizes. After confirming the quality and quantity, the next step of the experiment was planned.

\section{Western blot analysis of H.a-ALP level and its detection in M. separata and P. xylostella}

Western blot analysis was carried out to detect the level of H.a-ALP in the third, fourth, and fifth instars of H. armigera. Alkaline phosphatase was found to be in increasing or- 
der from the third to fifth instar larvae (Figure 9). After successfully detecting ALP of $58 \mathrm{kDa}$ from $H$. armigera, western blot analysis was performed to detect ALP from $M$. separata and P. xylostella using anti-pET32a-H.a-ALP. The results showed clear bands of almost $58 \mathrm{kDa}$ on the polyvinylidene difluoride membrane for both M. separata and P. xylostella (Figure 10).

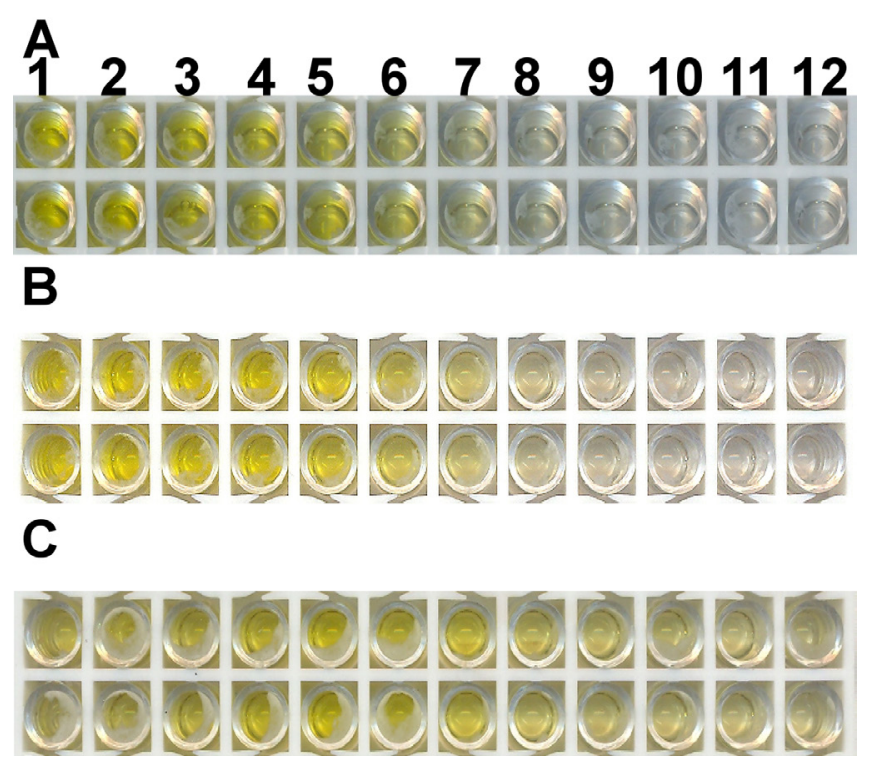

Figure 5. ELISA plates for the first, second and third test blood. A. ELISA plate for the first blood; B. ELISA plate for the second test blood; and C. ELISA plate for the third test blood.

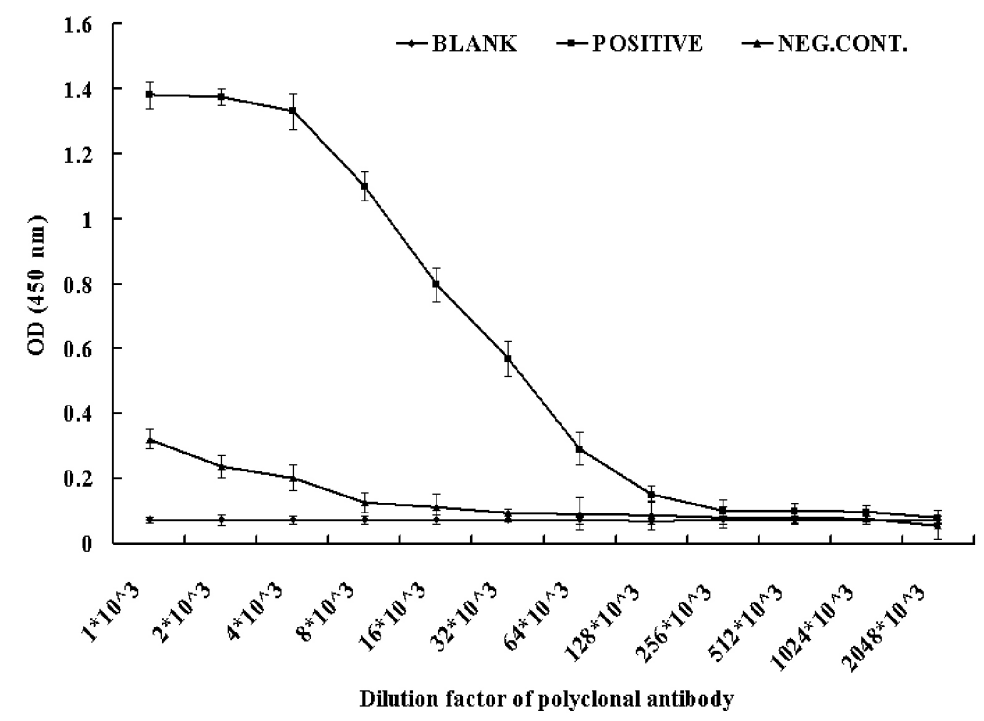

Figure 6. Determination of anti-pet32a-H.a-ALP antibody titer by micro-plate reader at $450 \mathrm{~nm}$ for the first test blood. 


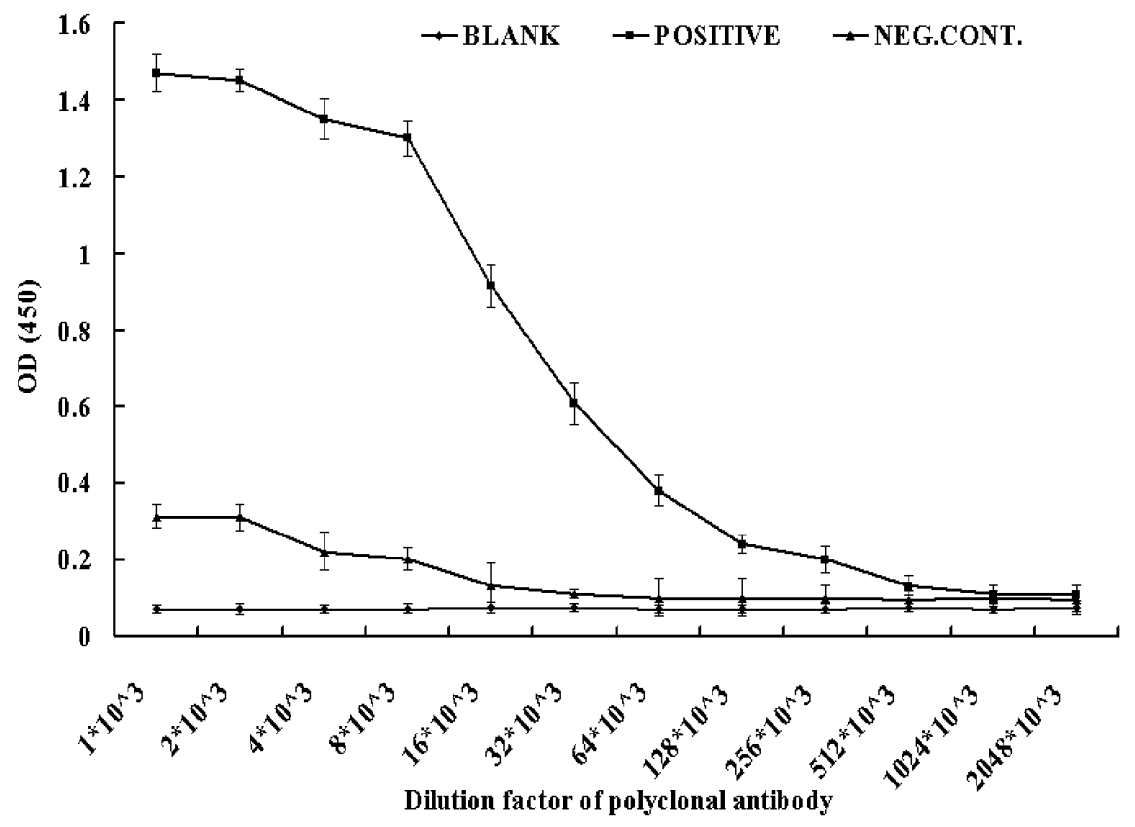

Figure 7. Determination of anti-pet32a-H.a-ALP antibody titer by micro-plate reader at $450 \mathrm{~nm}$ for the second test blood.

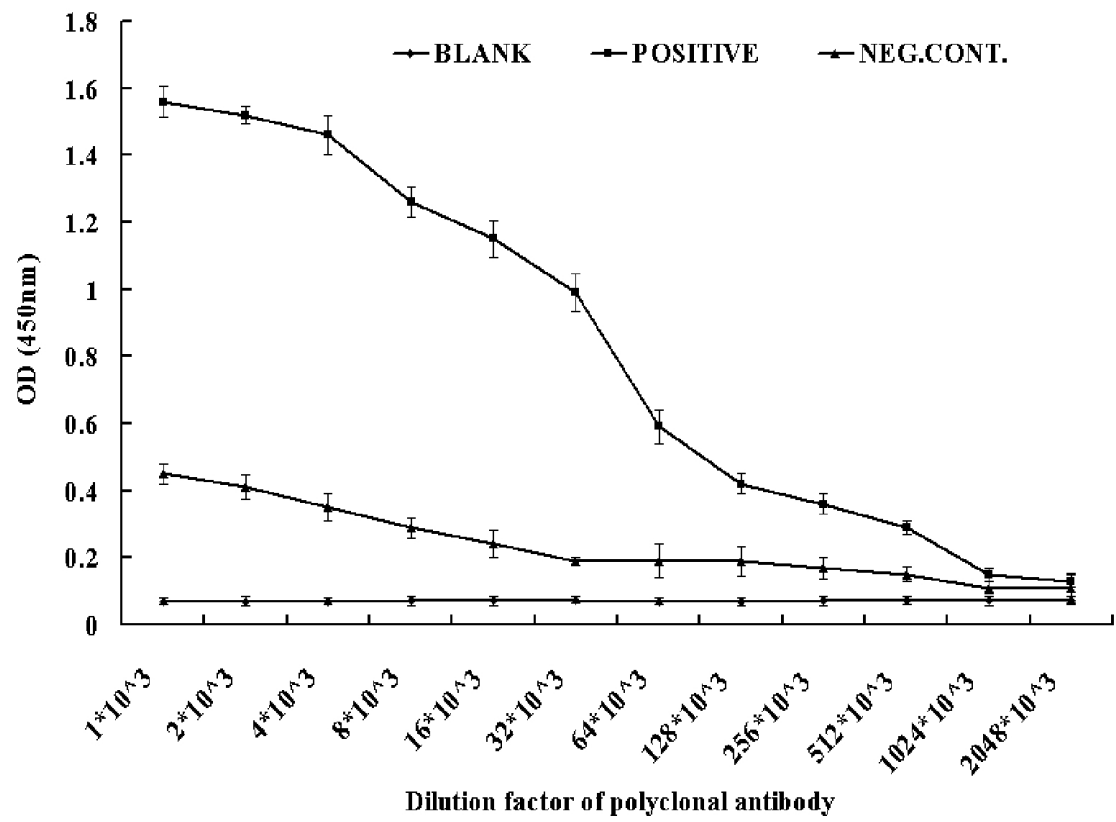

Figure 8. Determination of anti-pet32a-H.a-ALP antibody titer by micro-plate reader at $450 \mathrm{~nm}$ for the third test blood. 


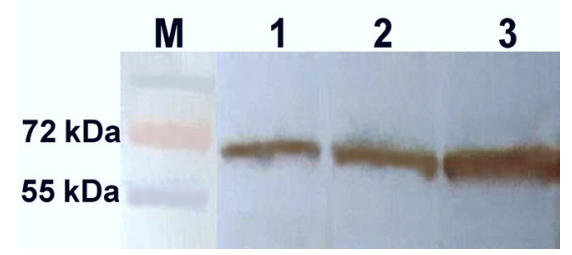

Figure 9. Western blot analysis of anti-pET32a-H.a-ALP antibody against H.a-ALP. Lane $M=$ prestained protein weight marker; lane 1-3 = ALP levels from 3rd, 4th, and 5th instar of Helicoverpa armigera. The Imagej software was used to calculate fold-change using the fluorescent intensity of each band.



Figure 10. Western blot analysis of anti-pET32a-H.a-ALP antibody. Lane $M=$ prestained protein weight marker; lane 1 = H.a-ALP; lane 2 = M.s-ALP; lane 3 = P.x-ALP.

\section{DISCUSSION}

Alkaline phosphatase is a very important ubiquitous enzyme that plays a crucial role in many physiological processes within the insect body. In addition to this, its high level has been attributed to insecticide resistance (Srinivas et al., 2004; Zibaee et al., 2009). The effective detection of ALP levels is therefore of great practical importance for pest management considerations.

In our experiment, we used pET-32a, which is a chemically induced type of fusion expression vector. A strong T7lac promoter gene upstream of the multiple cloning sites is helpful for the expression of the target gene. Other fusion tags facilitate detection and purification. The expressed amount of target protein is very high and is obtained as inclusion bodies. However, by adjusting the temperature and the concentration of IPTG, soluble recombinant protein could be obtained if required, but the majority of recombinant protein is still present as inclusion bodies. Our recombinant protein was $79 \mathrm{kDa}$, having $58.8 \mathrm{kDa}$ of H.a-ALP and the remaining part being of the fusion tag between the promoter and the multiple cloning sites. Expressed recombinant proteins may be purified by desalting, digestion by thrombin, affinity chromatography, and gel filtration. However, the expressed protein was not purified, but used directly after desalting for the production of polyclonal antibody. Detection of the ALP was however not affected.

Earlier, numerous studies have reported polyclonal antibodies produced using recombinant proteins obtained for the pheromone-binding proteins of $H$. armigera, Antheraea per$n y i$, and A. polyphemus, as well as for the general odorant-binding protein 2 of Manduca sexta and Mamestra brassicae (Krieger et al., 1992; Prestwich, 1993; Feng and Prestwich, 1997; 
Maibeche-Coisne et al., 1998; Wang et al., 2004). Polyclonal antibody was also used to detect the odorant-binding protein of $H$. armigera (Sun et al., 2012). In another report, polyclonal antibody was used to study the function of nuclear transport factor 2 and Ran in the 20E signal transduction pathway in $H$. armigera (He et al., 2010). However, a polyclonal antibody for the detection of ALP from $H$. armigera has not been reported previously.

In earlier studies, the level of ALP was detected by colorimetric methods in resistant and susceptible insects (Srinivas et al., 2004). However, immunodetection of its level renders a much greater degree of sensitivity than colorimetric assays. Immunodetection has been termed 10 times more sensitive than colorimetric assays (Maehira and Takaesu, 1987). Therefore, we believe our immunodetection of ALP and its level will provide a more accurate and gene-specific method for detection of resistance levels.

The anti-pET32a-H.a-ALP production was also optimized by phase-wise injection scheduling and titer determination by ELISA at the end of every phase, thereby improving the sensitivity of the detection process. We believe this procedure is much more robust, accurate, and specific than other methods previously used.

In summary, the recombinant protein produced by a prokaryotic expression vector produced an antibody that could not only effectively detect ALP in H. armigera, but also its levels in the worm. Using this antibody, ALP of almost similar size was also detected from $M$. separata and P. xylostella. This effective detection of ALP level could be of great significance to study ALP expression, tissue localization, and levels for insecticide resistance studies.

\section{CONCLUSION}

In light of our experimental results, we conclude that this antibody can specifically recognize ALP in the samples using ELISA or western blot analysis. It was also established that the antibody produced against H.a-ALP effectively detected ALP from other lepidopterans, showing the close homology of the ALP gene amongst these insects.

\section{ACKNOWLEDGMENTS}

Research supported by the Special Fund for the Public Interest (Agriculture) (\#200903052) by The Ministry of Science and Technology of China and The Ministry of Agriculture, China, and the ' 13115 ' Sci-Tech Innovation Project of Shaanxi Province (\#2007ZDKG-14).

\section{REFERENCES}

Ahmed M and McCaffery AR (1991). Elucidation of detoxification mechanisms involved in resistance to insecticides against third instar larvae of a field selected strain of Helicoverpa armigera with the use of synergists. Pestic. Biochem. Physiol. 41: 41-52.

Bhatnagar VS, Lateef SS, Sithanantham S, Pawar CS, et al. (1982). Research on Heliothis at ICRISAT. In: Proceedings of the International Workshop on Heliothis Management, 15-20 November, 1981, Patancheru, India.

Chang WS, Zachow KR and Bentley D (1993). Expression of epithelial alkaline phosphatase in segmentally iterated bands during grasshopper limb morphogenesis. Development 118: 651-663.

Chomczynski P (1993). A reagent for the single-step simultaneous isolation of RNA, DNA and proteins from cell and tissue samples. Biotechniques 15: 532-537.

Eguchi M (1995). Alkaline phosphatase isozymes in insects and comparison with mammalian enzyme. Comp. Biochem. 
Physiol. B Biochem. Mol. Biol. 111: 151-162.

EPPO (1996). EPPO Reporting Service, No. 6. EPPO, Paris.

Feng L and Prestwich GD (1997). Expression and characterization of a lepidopteran general odorant binding protein. Insect Biochem. Mol. Biol. 27: 405-412.

He HJ, Wang Q, Zheng WW, Wang JX, et al. (2010). Function of nuclear transport factor 2 and Ran in the 20E signal transduction pathway in the cotton bollworm, Helicoverpa armigera. BMC Cell Biol. 11: 1.

Horie B (1958). The alkaline phosphatase in the midgut of silkworm, Bombyx mori L. Bull. Sericultural Exp. Station 15: 275-289.

ICRISAT (2003). Annual Report. ICRISAT, Patancheru.

Krieger J, Raming K, Prestwich GD, Frith D, et al. (1992). Expression of a pheromone-binding protein in insect cells using a baculovirus vector. Eur. J. Biochem. 203: 161-166.

Kucera M and Weiser J (1974). Alkaline-phosphatase in last larval instar of Barathra brassicae (Lepidoptera) infected by Nosema plodiae. Acta Entomol. Bohemoslov 71: 289-293.

Maehira F and Takaesu I (1987). Dot immunodetection for sphingomyelinase with monoclonal antibody. Biochem. Med. Metab. Biol. 37: 5-15.

Maibeche-Coisne M, Longhi S, Jacquin-Joly E, Brunel C, et al. (1998). Molecular cloning and bacterial expression of a general odorant-binding protein from the cabbage armyworm Mamestra brassicae. Eur. J. Biochem. 258: 768-774.

Miao YG (2002). Studies on the activity of the alkaline phosphatase in the midgut of infected silkworm, Bombyx mori L. J. Appl. Entomol. 126: 138-142.

Prestwich GD (1993). Bacterial expression and photoaffinity labeling of a pheromone binding protein. Protein Sci. 2: 420-428.

Rauschenbach IY, Chentsova NA, Alekseev AA, Gruntenko NE, et al. (2007a). Dopamine and octopamine regulate 20-hydroxyecdysone level in vivo in Drosophila. Arch. Insect Biochem. Physiol. 65: 95-102.

Rauschenbach IY, Bogomolova EV, Gruntenko NE, Adonyeva NV, et al. (2007b). Effects of juvenile hormone and 20-hydroxyecdysone on alkaline phosphatase activity in Drosophila under normal and heat stress conditions. $J$. Insect Physiol. 53: 587-591.

Sakharov IY, Makarova IE and Ermolin GA (1989). Chemical modification and composition of tetrameric isozyme K of alkaline phosphatase from harp seal intestinal mucosa. Comp. Biochem. Physiol. B 92: 119-122.

Senthil-Nathan S, Kalaivani K, Murugan K and Chung PG (2005). The toxicity and physiological effect of neem limonoids on Cnaphalocrocis medinalis (Guenée) the rice leafolder. Pestic. Biochem. Physiol. 81: 113-122.

Srinivas R, Udikeri SS, Jayalakshmi SK and Sreeramulu K (2004). Identification of factors responsible for insecticide resistance in Helicoverpa armigera. Comp. Biochem. Physiol. C Toxicol. Pharmacol. 137: 261-269.

Sujak P, Ziemnicki K, Ziemnicka J, Lipa JJ, et al. (1978). Acid and alkaline-phosphatase activity in fat-body and midgut of beet armyworm, Spodoptera exigua (Lepidoptera: Noctuidae), infected with nuclear polyhedrosis virus. J. Invertebr. Pathol. 31: 4-9.

Sukhanova MJ, Grenback LG, Gruntenko NE and Khlebodarova TM (1996). Alkaline phosphatase in Drosophila under heat stress. J. Insect. Physiol. 42: 161-165.

Sun YL, Huang LQ, Pelosi P and Wang CZ (2012). Expression in antennae and reproductive organs suggests a dual role of an odorant-binding protein in two sibling Helicoverpa species. PLoS One 7: e30040.

Wang GR, Wu KM and Guo YY (2004). Molecular cloning and bacterial expression of pheromone binding protein in the antennae of Helicoverpa armigera (Hubner). Arch. Insect Biochem. Physiol. 57: 15-27.

Wright TRF (1987). Genetic of biogenic amines metabolism, sclerotisation and melanisation in Drosophila melanogaster. Adv. Genet. 24: 127-221.

Zibaee A, Sendi JJ, Ghadamyari M, Alinia F, et al. (2009). Diazinon resistance in different selected strains of Chilo suppressalis (Lepidoptera: Crambidae) in northern Iran. J. Econ. Entomol. 102: 1189-1196. 